\title{
Ectoparasitoses e saúde pública no Brasil: desafios para controle
}

\author{
Ecoparasitoses and public health in Brazil: \\ challenges for control
}

Jörg Heukelbach 1

Fabiola Araújo Sales de Oliveira 1

Hermann Feldmeier 2

1 Fundação Mandacaru.
Rua José Vilar de Andrade
257, Fortaleza, CE
$60833-830$, Brasil.
samsa@mcanet.com.br
2 Institute of International
Health, Center for
Humanities and Health
Sciences, Faculty of Medicine,
Free University of Berlin.
Fabeckstrasse 60-62, 12203,
Berlin, Germany.
feldmeier.fuberlin@t-online.de

\begin{abstract}
Parasitic skin diseases such as scabies, pediculosis, tungiasis, and cutaneous larva migrans are hyperendemic in the numerous poor communities in Brazil and are commonly associated with considerable morbidity. However, programs to control ectoparasites are non-existent in the country's public health system. Due to neglect of these diseases by the population itself and health care professionals, the diseases' highly contagious characteristics, and lack of effective treatment and/or presence of animal reservoirs together with a complex life cycle, effective control of ectoparasites is an enormous public health challenge. This article discusses potential measures to control parasitic skin diseases in affected communities, based on mass treatment, health education, and (when applicable) eradication of animal reservoirs.
\end{abstract}

Key words Ectoparasitic Infestations; Vulnerable Group; Urban Health; Health Surveillance

Resumo Doenças ectoparasitárias como a escabiose, a pediculose, a tungíase e a larva migrans cutânea são hiperendêmicas em inúmeras comunidades carentes no Brasil, e não raramente associadas à severidade considerável. Entretanto, programas que priorizem o controle de ectoparasitas não existem em nível de saúde pública no país. Como conseqüência da alta contagiosidade, de manejo inadequado, de negligência tanto da população como dos profissionais de saúde elou da presença de reservatórios animais, além de ciclos de vida complexos, o controle efetivo das ectoparasitoses é um desafio para a saúde pública. Aqui discutimos possíveis medidas de intervenção para o controle de doenças ectoparasitárias em comunidades afetadas, baseadas em tratamento em massa, educação em saúde e, caso se aplique, na erradicação dos reservatórios animais.

Palavras-chave Ectoparasitoses; Comunidades Vulneráveis; Saúde Urbana; Vigilância Sanitária 


\section{Introdução}

Doenças ectoparasitárias, como a pediculose, a escabiose, a tungíase e a larva migrans cutânea (LMC), são muito comuns em comunidades carentes no Brasil. É freqüente a presença de infestação severa e conseqüentes complicações. Apesar disso, programas de controle para essas doenças são quase inexistentes, e as mesmas estão comumente sendo negligenciadas tanto pelos profissionais e autoridades de saúde quanto pela população afetada (Heukelbach et al., 2003b). Como conseqüência, o controle de ectoparasitas em populações carentes tem sido raramente debatido no Brasil e em outros países onde doenças parasitárias são comuns (Heukelbach et al., 2002).

Estima-se que até dois terços da populacão de favelas de grandes cidades e de comunidades carentes rurais são afetados por pelo menos uma ectoparasitose, mais comumente pelo piolho, pelo ácaro Sarcoptes scabiei ("sarna”) e/ou pela pulga Tunga penetrans ("bicho de pé”) (Wilcke et al., 2002a).

\section{Pediculose, ftiríase e escabiose}

A pediculose é causada pela infestação pelo $P e$ diculus humanus corporis (piolho do corpo) ou pelo Pediculus humanus capitis (piolho do couro cabeludo). O tifo epidêmico (causado por Rickettsia prowazekii), a febre das trincheiras (causada por Bartonella quintana) e a febre recorrente (causada por Borrelia recurrentis) podem ser transmitidos pelo piolho do corpo (Fournier et al., 2002). O piolho do couro cabeludo nunca foi descrito como vetor para essas doenças, entretanto, a transmissão da Rickettsia prowazekii por esse ectoparasita foi demonstrada em laboratório. É possível que o $P$. humanus capitis seja agente transmissor da rickettsiose em epidemias que foram principalmente causadas pelo P. humanus corporis (Robinson et al., 2003).

O piolho do couro cabeludo comumente causa infecções secundárias e foi considerado uma das causas principais de impetigo nas populações de países em desenvolvimento (Burgess, 1995). As crianças infestadas podem apresentar baixo desempenho escolar por dificuldade de concentração, conseqüência do prurido contínuo e distúrbios do sono. Crianças com infestação severa também podem desenvolver anemia devido à hematofagia do piolho (Linardi, 2002).

Taxas de prevalência do piolho de couro cabeludo podem chegar a $40 \%$ em comunidades carentes no Brasil, sendo que crianças apresentam taxas mais altas (Wilcke et al., 2002a). A principal via de transmissão ocorre de cabeça a cabeça, sendo necessário um contato repetido e prolongado para atingir taxas de transmissão significantes (Canyon et al., 2002). A transmissão por meio de fômites é bastante discutível. Alguns autores consideram que essa via de transmissão desempenha papel significativo (Burkhart, 2003), porém, a sua importância em saúde pública ainda não está definida. Foi demonstrado que a transmissão em escolas não ocorre livremente de uma criança para outra, mas entre os amigos mais próximos (Burgess, 1995).

O piolho do corpo foi relatado somente em casos singulares no Município de São Paulo (Linardi et al., 1998), e não representa um problema de saúde pública no Brasil. Como tratamento, a desinfestação apropriada das roupas é medida suficiente na maioria dos casos.

A ftiríase ("chato") é causada pelo parasita Pthirus pubis. A biologia desse parasita é semelhante à do $P$. humanus capitis, sendo que aquele habita o pêlo da região púbica. Em casos singulares, o $P$. pubis pode também atingir outras partes do corpo como a barba, os cílios, os pêlos axilares e até o couro cabeludo. A transmissão ocorre por contato físico muito próximo, principalmente contato sexual. Dados populacionais sobre a ftiríase são inexistentes no nosso país.

A escabiose humana ("sarna") é causada pelo ácaro Sarcoptes scabiei var. hominis. O prurido cutâneo leva comumente a uma infecção secundária e é causado por uma reação alérgica a produtos metabólicos do ácaro. Glomerulonefrite aguda também foi associada à escabiose (Burgess, 1994). A transmissão ocorre por contato direto, inclusive sexual. A transmissão por meio de fômites pode ocorrer, porém em condições normais, o contato físico é a única via de transmissão de importância epidemiológica (Burgess, 1994). Condições sócioeconômicas precárias, aglomerações, não aderência aos tratamentos tópicos comumente utilizados e o desenvolvimento de resistência medicamentosa são os grandes responsáveis pela manutenção de altas taxas de prevalência, especialmente em populações carentes. Nesse meio, a prevalência atinge cerca de $10 \%$ (Wilcke et al., 2002a).

O controle efetivo da pediculose e da escabiose em saúde pública deve ser baseado no tratamento em massa associado à educação em saúde. O tratamento em massa da escabiose com ivermectina ou com piretróides foi demonstrado como eficiente em comunidades 
carentes, a exemplo de estudos em uma aldeia em Papua, Nova Guiné (Bockarie et al., 2000) e em uma comunidade de aborígines na Austrália (Carapetis et al., 1997). A ivermectina demonstrou ser igualmente eficaz ao benzoato de benzila no tratamento da escabiose (Brooks \& Grace, 2002); entretanto, a efetividade na comunidade deve ser ainda melhor para a ivermectina devido à praticidade de uso e conseqüente maior aderência ao tratamento. A ivermectina também é uma droga de alta eficácia para o tratamento da pediculose (Glaziou et al., 1994).

Em um estudo em uma comunidade de pescadores de cerca de 600 habitantes no Estado do Ceará, baixamos a taxa de prevalência de pediculose ativa de 16 para $1 \%$ e da escabiose de 4 para $1 \%$, com tratamento em massa com duas doses de ivermectina no intervalo de dez dias (Heukelbach et al., submitted).

A repetição da dose de ivermectina se faz necessária pelo fato da droga ser eficaz somente contra formas adultas dos parasitas, sendo que os ovos não são atingidos. Além disso, indivíduos que eventualmente tenham sido infestados por fômites no intervalo entre uma dose e outra, são tratados com a segunda dose.

Especialmente no controle da escabiose, é necessário o tratamento de todos os membros da família do indivíduo acometido e dos parceiros sexuais, inclusive dos assintomáticos. Nesse caso, não há necessidade de lavar e/ou tratar a roupa, pois o ácaro não sobrevive muito tempo fora do hospedeiro humano (Burgess, 1994). Infelizmente, o tratamento extensivo aos contatos mais próximos do indivíduo acometido raramente acontece, seja por falta de informação da população, pela negligência dos profissionais de saúde ou ainda pela não aderência do paciente ao tratamento tópico com benzoato de benzila, substância que causa ardor, de odor forte, que exige várias aplicações e único medicamento para escabiose disponível nas farmácias básicas do SUS.

Para controlar a pediculose nas escolas, o simples tratamento e isolamento de crianças afetadas não é suficiente. Como a sensibilidade do diagnóstico clínico não é muito alta e por ser a ivermectina uma droga altamente eficaz contra a pediculose e outras parasitoses, de aplicação prática (dose única oral) e segura (raros efeitos colaterais), recomenda-se o tratamento em massa de todas as crianças, independente de exame clínico, com essa droga. O tratamento baseado na aplicação de substâncias tópicas é particularmente problemático devido à baixa adesão e à presença de resistência do parasita a várias dessas substâncias. O benzoa- to de benzila, amplamente utilizado no Brasil para o tratamento da escabiose, é irritante, pode causar dermatite e não é recomendado para crianças. Os piretróides, apesar do maior custo, têm a vantagem de ser menos irritante, de odor menos desagradável e podem ser aplicados em crianças pequenas, ao contrário da ivermectina, contra-indicada em menores de cinco anos, crianças de peso inferior a $15 \mathrm{~kg}$, grávidas, nutrizes e indivíduos com afecções do sistema nervoso central.

A ivermectina ainda não foi utilizada extensivamente em saúde pública no Brasil, porém vem sendo utilizada há anos em milhões de pessoas na África como tratamento em massa contra filariose em áreas endêmicas, tendo se mostrado uma droga efetiva, segura e com poucos efeitos colaterais (Stephenson \& Wiselka, 2000). A utilização da ivermectina, além da alta praticidade, apresenta baixo custo.

\section{Tungíase e larva migrans cutânea}

A tungíase é causada pela penetração e subseqüente hipertrofia da fêmea da pulga T. penetrans na epiderme do hospedeiro. As áreas preferenciais de penetração no homem são os pés nas áreas interdigitais. Complicações comuns incluem a infecção bacteriana secundária, a perda de unha e a deformação de dígitos (Feldmeier et al., 2002, 2003).

Em comunidades carentes brasileiras, recentemente foram documentadas taxas de prevalência entre 34 e 55\% (Carvalho et al., 2003; Muehlen et al., in press; Wilcke et al., 2002b).

Animais domésticos e ratos são reservatórios importantes. Em um estudo em uma favela de Fortaleza, Ceará, $67 \%$ dos cães, $50 \%$ dos gatos e $41 \%$ dos ratos capturados estavam infestados com T. penetrans (Heukelbach et al., 2003a). Em áreas rurais, os porcos também são reservatórios; porém, com o confinamento desses animais às pocilgas, sua importância na epidemiologia da doença tem diminuído nos últimos anos.

É provável que ovos, larvas e pupas da pulga sobrevivam no meio ambiente por semanas ou até meses. Devido à existência de reservatórios animais distintos e à sobrevivência da pulga no seu habitat natural por tempo prolongado sem a necessidade de hospedeiro, o controle da tungíase torna-se um desafio particular (Heukelbach et al., 2002).

Além disso, não é conhecida nenhuma quimioterapia eficaz para eliminar pulgas penetradas, nem em seres humanos, nem em animais. O tratamento atual consiste na retirada 
das pulgas penetradas com uma agulha estéril e tratamento de infecções secundárias com antibiótico, medidas de pouca viabilidade para tratamento de comunidades inteiras (Heukelbach et al., 2001).

Como há uma aparente preferência da $T$. penetrans por solo arenoso e de pouca luminosidade, a pavimentação das vias públicas e a cimentação dos pisos das casas se apresentam como importantes medidas de controle. Saneamento básico, principalmente coleta regular de lixo, certamente contribuirão para reduzir incidência e severidade. Como essas medidas claramente demandam um maior investimento tanto da população como das autoridades locais, além de não serem factíveis em curto prazo, levando-se em consideração a realidade político-econômica brasileira, o controle ambiental com inseticidas seria uma outra opção. Entretanto, as áreas infestadas são geralmente de grandes dimensões e o custo do tratamento dos animais domésticos com inseticidas é considerável. Obviamente, a eliminação da população de ratos não deve ser esquecida.

Não se pode ignorar a percepção da população em relação à tungíase. Comumente, essa ectoparasitose não é percebida como doença (Heukelbach et al., 2003b). A educação em saúde deve priorizar - além de medidas gerais de higiene - a prevenção secundária (educar a população para o auto-exame diário e para a retirada adequada das pulgas penetradas com instrumento estéril). A prevenção primária (usar sapatos fechados) é claramente não factível em áreas endêmicas.

A LMC é causada pela penetração de larvas de ancilostomídeos, normalmente de cães e gatos, na pele do homem. A infestação ocorre após contato com solo contaminado com as fezes desses animais. Como o ser humano não é o hospedeiro apropriado, as larvas não conseguem chegar a seu destino programado e continuam migrando na epiderme durante várias semanas. Como o prurido é intenso, a LMC comumente leva a distúrbios do sono e a infecções secundárias. A prevalência da LMC em uma favela de Fortaleza, Ceará, foi estimada em 3\% (Heukelbach et al., in press).

A infestação no homem é autolimitada e as larvas não se desenvolvem nesse hospedeiro acidental; por isso, o tratamento de pessoas infestadas não apresenta nenhum impacto na transmissão da doença. O tratamento periódico do reservatório animal - cães e gatos - com anti-helmínticos é indispensável para o controle dessa ectoparasitose.

O quadro é particularmente desafiador em populações carentes, onde é comum a presen- ça de animais vadios e onde o desconhecimento acerca da importância do tratamento dos animais domésticos e limitações financeiras impossibilitam essas medidas. Conseqüentemente, a educação em saúde, priorizando o uso de calçados e um programa em parceria população-governo de tratamento periódico dos animais domésticos, parece ser a melhor opção para a prevenção da LMC.

O tratamento do indivíduo acometido com LMC consiste na aplicação tópica de tiabendazol, albendazol via oral ou ivermectina via oral (Caumes, 2003). Infelizmente, nenhuma dessas drogas faz parte da lista de medicamentos essenciais do Ministério da Saúde.

\section{Conclusão}

Parece óbvio que somente um esforço em conjunto população-ações governamentais, incluindo educação em saúde, saneamento básico e tratamento em massa podem alcançar sucesso duradouro no controle das doenças ectoparasitárias mais importantes em nosso meio. O mapeamento de áreas endêmicas e de alto risco, a busca ativa de casos e o tratamento dos contatos podem ser realizados em parceria com o Programa Saúde da Família e a Fundação Nacional de Saúde, cujas ações se desenvolvem no contato direto com a comunidade.

Conceitos como estigmatização, vergonha e negligência devem fazer parte da educação em saúde tanto para as populações afetadas, como para os profissionais de saúde.

Apesar da dimensão do problema, o conhecimento atual em relação às ectoparasitoses é ainda escasso. É indispensável não somente incrementar o conhecimento sobre a epidemiologia das ectoparasitoses em nosso meio, como também avaliar o potencial de inseticidas modernos e a terapia medicamentosa no combate à T. penetrans nos hospedeiros e no ambiente.

A melhoria da qualidade de vida das populações carentes no nosso país não se faz de um momento para o outro. Mas medidas de controle efetivas e eficientes para as ectoparasitoses são factíveis. Um programa de controle de ectoparasitoses incluiria também o controle de verminoses intestinais pelo fato da ivermectina ser também efetiva contra essas doenças. $\mathrm{O}$ tratamento em massa com ivermectina a cada seis meses, associado à educação em saúde com participação popular é medida extremamente custo-efetiva. Em médio prazo, os custos da assistência primária seriam reduzidos pela queda na procura de atendimento atribuído às verminoses e ectoparasitoses. Como a 
qualidade de vida é dependente do nível de saúde de uma população, seria mais um passo no alcance de uma melhor qualidade de vida para todos.

\section{Agradecimentos}

Esse trabalho foi apoiado pelo "Ärztekommittee für die Dritte Welt”, Frankfurt (Alemanha).

\section{Referências}

BOCKARIE, M. J.; ALEXANDER, N. D. E.; KAZURA, J. W.; BOCKARIE, F.; GRIFFIN, L. \& ALPERS, M. P., 2000. Treatment with ivermectin reduces the high prevalence of scabies in a village in Papua New Guinea. Acta Tropica, 75:127-130.

BROOKS, P. A. \& GRACE, R. F., 2002. Ivermectin is better than benzyl benzoate for childhood scabies in developing countries. Journal of Pediatrics and Child Health, 38:401-404.

BURGESS, I. F., 1994. Sarcoptes scabiei and Scabies. Advances in Parasitology, 33:235-292.

BURGESS, I. F., 1995. Human lice and their management. Advances in Parasitology, 36:271-342.

BURKHART, C. N., 2003. Fomite transmission with head lice: A continuing controversy. Lancet, 361: 99-100.

CANYON, D. V.; SPEARE, R. \& MULLER, R., 2002. Spatial and kinetic factors for the transfer of head lice (Pediculus capitis) between hairs. Journal of Investigative Dermatology, 119:629-631.

CARAPETIS, J. R.; CONNORS, C.; YARMIRR, D.; KRAUSE, V. \& CURRIE, B. J., 1997. Success of a scabies control program in an Australian aboriginal community. Pediatric Infectious Diseases Journal, 16:494-499.

CARVALHO, R. W.; ALMEIDA, A. B.; BARBOSA-SILVA, S. C.; AMORIM, M.; RIBEIRO, P. C. \& SERRAFREIRE, N. M., 2003. The patterns of tungiasis in Araruama township, State of Rio de Janeiro, Brazil. Memórias do Instituto Oswaldo Cruz, 98:31-36.

CAUMES, E., 2003. Treatment of cutaneous larva migrans and Toxocara infection. Fundamentals of Clinical Pharmacology, 17:213-216.

FELDMEIER, H.; EISELE, M.; SABÓIA-MOURA, R. C. \& HEUKELBACH, J., 2003. Severe tungiasis - A resurgent health problem in deprived populations? A case series from Northeast Brazil. Emerging Infectious Diseases, 9:949-955.
FELDMEIER, H.; HEUKELBACH, J.; EISELE, M.; SOUSA, A. Q.; BARBOSA, L. M. \& CARVALHO, C. B., 2002. Bacterial superinfection in human tungiasis. Tropical Medicine and International Health, 7:559-564.

FOURNIER, P.-E.; NDIHOKUBWAYO, J.-B.; GUIDRAN, J.; KELLY, P. J. \& RAOULT, D., 2002. Human pathogens in body and head lice. Emerging Infectious Diseases, 8:1515-1518.

GLAZIOU, P.; NYGUYEN, L. N.; MOULIA-PELAT, J. P.; CARTEL, J. L. \& MARTIN, P. M. V., 1994. Efficacy of ivermectin for the treatment of head lice (Pediculosis capitis). Tropical and Medical Parasitology, 45:253-254.

HEUKELBACH, J.; COSTA, A. M. L.; WILCKE, T.; MENCKE, N. \& FELDMEIER, H., 2003a. The animal reservoir of Tunga penetrans in severely affected communities in northeast Brazil. Medical and Veterinarian Entomology, 17.

HEUKELBACH, J.; MENCKE, N. \& FELDMEIER, H., 2002. Cutaneous larva migrans and tungiasis: The challenge to control zoonotic ectoparasitoses associated with poverty. Tropical Medicine and International Health, 7:907-910.

HEUKELBACH, J.; OLIVEIRA, F. A. S.; HESSE, G. \& FELDMEIER, H., 2001. Tungiasis: A neglected health problem of poor communities. Tropical Medicine and International Health, 6:267-272.

HEUKELBACH, J.; van HAEFF, E.; RUMP, B.; WILCKE, T.; MOURA, R. C. \& FELDMEIER, H., 2003b. Parasitic skin diseases: Health care-seeking in a slum in Northeast Brazil. Tropical Medicine and International Health, 8:368-373.

HEUKELBACH, J.; WILCKE, T. \& FELDMEIER, H., in press. Cutaneous larva migrans (creeping eruption) in an urban slum in Brazil. International Journal of Dermatology.

HEUKELBACH, J.; WINTER, B.; WILCKE, T.; OLI- 
VEIRA, F. A. S.; SABÓIA-MOURA, R. C.; HARMS, G.; LIESENFELD, O. \& FELDMEIER, H., submitted. Efficacy of ivermectin in a population concomitantly infected with intestinal helminths and ectoparasites. Drug Research.

LINARDI, P. M., 2002. Anoplura. In: Parasitologia Humana (D. P. Neves, A L. Melo, O. Genaro \& P. M. Linardi, org.), pp. 368-372, São Paulo: Editora Atheneu.

LINARDI, P. M.; BARATA, J. M. S.; URBINATTI, P. R.; SOUZA, D.; BOTELHO, J. R. \& MARIA, M., 1998. Infestação por Pediculus humanus (Anoplura: Pediculidae) no Município de São Paulo, SP, Brasil. Revista de Saúde Pública, 32:77-81.

MUEHLEN, M.; HEUKELBACH, J; WILCKE, T.; WINTER, B.; MEHLHORN, H. \& FELDMEIER, H., in press. Investigations on the biology, epidemiology, pathology and control of Tunga penetrans in Brazil: II. Prevalence, parasite load and topographic distribution of lesions in a traditional fishing village. Parasitology Research.
ROBINSON, D.; LEO, N.; PROCIV, P. \& BARKER, S. C., 2003. Potential role of head lice, Pediculus humanus capitis, as vectors of Rickettsia prowazekii. Parasitology Research, 90:209-211.

STEPHENSON, I. \& WISELKA, M., 2000. Drug treatment of tropical parasitic infections. Drugs, 60: 985-995.

WILCKE, T.; HEUKELBACH, J.; SABÓIA-MOURA, R. C. \& FELDMEIER, H., 2002a. Scabies, pediculosis, tungiasis and cutaneous larva migrans in a poor community in northeast Brazil. Acta Tropica, 83 (Sup. 1):S100.

WILCKE, T.; HEUKELBACH, J.; SABÓIA-MOURA, R. C.; KERR-PONTES, L. R. S. \& FELDMEIER, H., $2002 \mathrm{~b}$. High prevalence of tungiasis in a poor neighbourhood in Fortaleza, Northeast Brazil. Acta Tropica, 83: 255-258.

Submetido em 14 de abril de 2003

Versão final reapresentada em 9 de maio de 2003 Aprovado em 3 de junho de 2003 